\title{
Healthcare professionals' perspectives of barriers and facilitators in implementing physical activity programmes delivered to cancer survivors in a shared-care model: a qualitative study
}

\author{
Charlotte IJsbrandy ${ }^{1,2,3}$ - Wim H. van Harten ${ }^{4,5}$ • Winald R. Gerritsen ${ }^{2}$ - Rosella P.M.G. Hermens ${ }^{1}$ • \\ Petronella B. Ottevanger ${ }^{2}$
}

Received: 12 June 2019 / Accepted: 30 September 2019 / Published online: 2 December 2019

(C) The Author(s) 2019

\begin{abstract}
Background The positive impact of physical activity programmes has been recognised, but the current uptake is low. Authorities believe delivering these programmes in a shared-care model is a future perspective. The present study aimed to identify the barriers and facilitators affecting physical activity programme implementation in a shared-care model delivered with the cooperation of all the types of healthcare professionals involved.

Methods Thirty-one individual interviews with primary healthcare professionals (PHPs) and four focus group interviews with 39 secondary healthcare professionals (SHPs) were undertaken. We used Grol and Flottorp's theoretical models to identify barriers and facilitators in six domains: (1) physical activity programmes, (2) patients, (3) healthcare professionals, (4) social setting, (5) organisation and (6) law and governance.

Results In the domain of physical activity programmes, those physical activity programmes that were non-tailored to the patients' needs impeded successful implementation. In the domain of healthcare professionals, the knowledge and skills pertaining to physical activity programmes and non-commitment of healthcare professionals impeded implementation. HCPs expressed their concerns about the negative influence of the patient's social network. Most barriers occurred in the domain of organisation. The PHPs and SHPs raised concerns about ineffective collaboration and networks between hospitals. Only the PHPs raised concerns about poor communication, indeterminate roles, and lack of collaboration with SHPs. Insufficient and unclear insurance coverage of physical activity programmes was a barrier in the domain of law and governance.

Conclusions Improving the domain of organisation seems the most challenging because the collaboration, communication, networks, and interactive roles between the PHPs and SHPs are all inadequate. Survivor care plans, more use of health information technology, improved rehabilitation guidelines, and better networks might benefit implementing physical activity programmes.
\end{abstract}

Keywords Exercise $\cdot$ Health plan implementation $\cdot$ Neoplasms $\cdot$ Qualitative research $\cdot$ Rehabilitation $\cdot$ Cancer survivors

Electronic supplementary material The online version of this article (https://doi.org/10.1007/s00520-019-05108-1) contains supplementary material, which is available to authorized users.

Charlotte IJsbrandy

Charlotte.IJsbrandy@Radboudumc.nl

Wim H. van Harten

W.v.Harten@NKI.nl

Winald R. Gerritsen

Winald.Gerritsen@Radboudumc.nl
Rosella P.M.G. Hermens

Rosella.Hermens@Radboudumc.nl

Petronella B. Ottevanger

Nelleke.Ottevanger@Radboudumc.nl

Extended author information available on the last page of the article 


\section{Background}

There is a distinct deterioration of the patient's physical activity during cancer treatment. It is also well known that patients' physical activity levels are generally lower even after they have completed their cancer treatment [1]. However, the positive impact of physical activity programmes on these patients has recently been recognised and has been shown to improve both psychological and physiological functions [2-6]. Therefore, evidence-based guidelines recommend physical activity programmes or the use of other initiatives to improve the uptake of physical activity during and after cancer and its treatment. Nonetheless, it appears that current uptake is low [7-10].

The success of implementing physical activity programmes depends on the care model that makes provision for these programmes. Survivor care had been traditionally delivered by secondary healthcare professionals (SHPs). However, concern exists about the sustainability of this care route in the face of the continuing increase of cancer survivors $[11,12]$. A shared-care model with care partly shifted to primary healthcare professionals (PHPs) may be a solution. It might optimise adherence to guidelines for recommended follow-up and rehabilitation of cancer survivors [13]. Authorities believe that a shared-care model is needed to provide qualitative and cost-effective survivor care in the future $[14,15]$. Therefore, evidencebased guidelines recommend physical activity programmes delivered in a shared-care model. In the context of our study, a shared-care model is an organisational model involving both PHPs and SHPs working together as a team. Screening, referral, and delivery of physical activity programmes should be offered partly by PHPs and partly by SHPs, depending on the needs of the cancer survivor. However, concerns exist because the collaboration between primary care and secondary care is still lagging [16]. There are many barriers, and only a few PHPs and SHPs prefer a shared-care model for cancer survivors [17-22].

Those researching the factors affecting physical activity programme implementation should also take into account the effects of delivering physical activity programmes in a shared-care model. This model might be more challenging than traditional models since it involves more healthcare professionals (HCPs) in both primary and secondary care. However, since the shared-care model for cancer survivors is the model of the future for providing screening, referral, and delivery of physical activity programmes, more insight into the barriers and facilitators affecting physical activity programme implementation in this model is needed. Therefore, the present exploratory and qualitative study aimed to identify the barriers and facilitators affecting physical activity programme implementation delivering in a shared-care model.

\section{Methods}

Individual and focus group interviews provided data about the factors affecting physical activity programme implementation in a shared-care model delivered by PHPs and SHPs. This qualitative study was carried out following the Consolidated criteria for Reporting Qualitative studies (COREQ) [23]. We invited HCPs who should be involved in the screening, referral, and delivery of physical activity programmes in the shared-care model. Five hospitals in the Netherlands (one categorical, one university, one teaching and two nonteaching) were invited to participate in this qualitative study.

\section{Setting}

In the Dutch healthcare system, physical activity programmes are offered by (1) rehabilitation physicians in hospitals or rehabilitation clinics; apart from physical problems, patients also need to have been diagnosed with psychological or social problems to be allowed to participate in these physical activity programmes; (2) multiple HCPs (e.g. sports-medicine physicians, physiotherapists) or by non-HCPs such as sports trainers; these programmes are mainly offered outside of the hospitals. The majority (>70\%) of patients only attends the second physical activity programmes.

The Dutch healthcare system is a managed competition based healthcare system [24]. The financing includes a mandatory universal basic health insurance that provides financial coverage of a comprehensive and uniform package of health services. Dutch residents can also obtain additional health insurance. The physical activity programmes that rehabilitation physicians offer are mainly covered by the basic health insurance, yet they are only available for cancer survivors with multidimensional problems. For the other, mostly monodisciplinary physical activity programmes the financial coverage is sometimes guaranteed by additional health insurance. These physical activity programmes need to be financed mainly by the patients themselves.

\section{Study population}

\section{PHPs}

As a sampling technique we used purposeful sampling. Individual interviews were conducted with PHPs involved in the treatment of patients with cancer in primary care. The PHPs were practicing in the region of the five participating hospitals (e.g. general practitioners (GPs) and physiotherapists). The PHPs were asked to participate by letter and could reply to accept. One researcher (CIJ) phoned the PHPs who agreed to participate to inform them about the study and to answer their questions. The PHPs also received written information stating the objectives and the process of the individual 
interview. Then, the researcher made appointments for interviews with the participants.

\section{SHPs}

Four of the five hospitals (one categorical, one university, one teaching, and one non-teaching) participated in this qualitative focus group study. Seven to 13 SHPs treating cancer patients in secondary care were invited from each hospital (e.g. surgeons, radiotherapists, medical oncologists, gynaecologists, urologists, rehabilitation physicians, sports-medicine physicians, physiotherapists, physician assistants, nurses and psychologists). The SHPs were invited by e-mail, to which they could reply. Meetings were arranged in all the participating hospitals to inform the SHPs about the study and to answer their questions. Then the researcher determined the time and place of the focus group interviews.

\section{Data collection}

The HCPs were informed about the study, then informed consent and permission to audiotape the interviews was obtained. The HCPs were asked (also before the interviews began) to fill in a questionnaire about their age, gender, years of practice, function and specialty.

We developed three interview guides with Grol [25] and Flottorp's [26] theoretical models for identification of factors influencing implementation of care innovations. Based on the theoretical models of Grol and Flottorp the influencing factors had been coded in the following six domains: (1) characteristics of the physical activity programmes, (2) characteristics of the patients, (3) characteristics of the HCPs, (4) characteristics of the social setting, (5) characteristics of the organisation and (6) characteristics of the law and governance.

The interviews were structured as follows: we asked the HCPs to describe their experiences with physical activity programmes delivered in a shared-care model for survivors. As soon as barriers or facilitators came up, we explored them in detail, using the theoretical frameworks. The interviews gave the HCPs a chance to talk freely, as well as to express their personal feelings about the barriers to and facilitators of optimal delivered physical activity programmes for patients with or after cancer. The individual interviews took about $30 \mathrm{~min}$ each and were conducted by one experienced researcher (CIJ). The focus group interviews took about $90 \mathrm{~min}$ each and were conducted by two experienced researchers (CIJ and $\mathrm{RH})$. New interviews were performed until saturation was reached.

\section{Planned analytic approach and outcomes}

$\mathrm{Al}$ interviews were audio-taped and afterwards literally typed up verbatim in manuscripts, using Microsoft Word. These manuscripts were imported and analysed in qualitative software package Atlas.ti. We used version 7.6 .16 for this purpose. The content analysis process, as described by Elo et all [27] was used as methodology for the analysis. Two researchers qualitatively and independently coded the barriers and facilitators mentioned in the manuscript of the interviews. We coded the influencing factors in one of the six domains. Identified factors previously not present in the models were added. The two researchers (CIJ and LB) discussed their interpretation until consensus was reached. This was done separately for the individual PHP interviews and the SHP focus group interviews. We compared the outcomes for the PHPs and SHPs to find similarities and differences among the barriers.

\section{Results}

\section{Characteristics of the PHPs}

Table 1 outlines the characteristics of the PHPs. Individual interviews were conducted with 31 PHPs, of whom 7 came from the region of the categorical hospital, 3 from the region of the university hospital, 8 from the region of the teaching hospital, and 8 and 5 from the region of the two non-teaching hospitals.

The mean age of the PHPs who participated in the individual interviews was 47.5 years. Of the PHPs, $51.6 \%$ were women and $48.4 \%$ were men. Most had a Dutch background.

Table 1 Characteristics of primary healthcare professionals

\begin{tabular}{ll}
\hline Age (years) & $\begin{array}{l}\text { Mean 47.5, SD (10.8), range (30-63) } \\
\boldsymbol{n}(\boldsymbol{\%})\end{array}$ \\
Total & $31(100)$ \\
Gender & $15(48.4)$ \\
Male & $16(51.6)$ \\
Female & \\
Nationality & $30(96.8)$ \\
Dutch & $1(3.2)$ \\
American & \\
Function & $14(45.2)$ \\
General practitioner & $17(54.8)$ \\
Physiotherapist & \\
Years in profession & $2(6.5)$ \\
$<1$ year & $1(3.2)$ \\
1-2 years & $5(16.1)$ \\
2-5 years & $5(16.1)$ \\
5-10 years & $17(54.8)$ \\
10-19 years & $1(3.2)$ \\
$>$ 20 years & \\
Type of hospital & $7(22.6)$ \\
Categorical & $3(9.7)$ \\
University & $8(25.8)$ \\
Teaching & $8(25.8)$ \\
Non-teaching 1 & $5(16.1)$ \\
Non-teaching 2 & \\
\hline
\end{tabular}


Fourteen PHPs were GPs and 17 were physiotherapists; $74.1 \%$ of the participants had more than 5 years of professional experience.

All the physiotherapists were aware of the existence of physical activity programmes and were involved in a physical activity programme. Among the GPs, $64.3 \%$ were aware of the existence of physical activity programmes and $28.6 \%$ had previously referred patients to physical activity programmes.

\section{Characteristics of the SHPs}

Table 2 shows the characteristics of the SHPs. The four group discussions were conducted with a total of 39 SHPs. Thirteen SHPs worked in the categorical hospital, 7 in the university hospital, 7 in the teaching hospital and 12 in the non-teaching hospital. The mean age of the SHPs who participated in the focus-groups was 43.2 years. The SHPs consisted of $82.1 \%$ women and $17.9 \%$ men. Most had a Dutch background.

Physicians and surgeons made up $33.3 \%$ of the SHPs involved in the focus group; paramedics, $30.6 \%$; nurses, $33.3 \%$; and $2.8 \%$ had a different profession (spiritual counsellor). Altogether, $71.8 \%$ of the focus group participants had more than 5 years of professional experience. All the SHPs were aware of the existence of physical activity programmes; $92.3 \%$ had

Table 2 Characteristics of secondary healthcare professionals

\begin{tabular}{ll}
\hline Age (years) & $\begin{array}{l}\text { Mean 43.2, SD (10.9), range (24-68) } \\
\boldsymbol{n}(\boldsymbol{\%})\end{array}$ \\
Total & $39(100)$ \\
Gender & \\
Male & $7(17.9)$ \\
Female & $32(82.1)$ \\
Nationality & \\
Dutch & $36(92.3)$ \\
German & $1(2.6)$ \\
Non-Western & $1(2.6)$ \\
Missing & $1(2.6)$ \\
Function & \\
Physician or Surgeon & $13(33.3)$ \\
Paramedic & $12(30.6)$ \\
Nurse & $13(33.3)$ \\
Other & $1(2.8)$ \\
Years in profession & \\
$<1$ year & $1(2.6)$ \\
1-2 years & $4(10.3)$ \\
2-5 years & $6(15.3)$ \\
5-10 years & $10(25.6)$ \\
10-19 years & $14(35.9)$ \\
$>$ 20 years & $4(10.3)$ \\
Name hospital & \\
Categorical & $13(33.3)$ \\
University & $7(17.9)$ \\
Teaching & $7(17.9)$ \\
Non-teaching 1 & $12(30.8)$ \\
\hline
\end{tabular}

referred patients to physical activity programmes, and $51.2 \%$ were involved in physical activity programmes themselves.

\section{Factors affecting PCRP implementation}

The qualitative individual and focus group analyses uncovered a wide variety of main themes for barriers and/or facilitators in the six domains. We qualitatively analysed the interviews in two categories: (1) themes of barriers and/or facilitators reported by PHPs (outlined in Table 3) and (2) themes of barriers and/or facilitators reported by SHPs (outlined in Table 4). The most important barriers and/or facilitators, and the differences between PHPs and SHPs are outlined here.

\section{Domain of physical activity programmes}

Both PHPs and SHPs said that they believed that physical activity programmes should be tailored to the needs of the patient. They also indicated that inadequate evidence about the effects of physical activity programmes was an impediment to their use. Additionally, PHPs said that the absence of consensus on these programmes also impeded their use. They pointed out that contact with peers who had experience in dealing with cancer and its treatments was a facilitator that encouraged patients to join a physical activity programme. Moreover, PHPs thought that clearly indicating the goals of the physical activity programmes could also help in the implementation of these programmes. Quotes illustrating the barriers and facilitator in the domain of physical activity programmes are:

"Tailored care. Really for the individual patient."

"I think that that offers possibilities for the uncomplicated patients. But now I can imagine some people about whom I think, "That wouldn't work for them." But you have to consider that for each patient."

\section{Domain of patients}

The interviewed PHPs en SHPs expressed their concerns that some patients could not afford the physical activity programmes. The physical activity programme itself might be too costly, but the additional travel expenses and the necessary sports attributes might also be unaffordable. They had thought about the lack of patients' knowledge about their own health and healthcare process. This might make patients hesitate to participate because of fear of doing more harm than good with such physical activity programme. It might also stop them from fully participating in a shared-care model for cancer survivors. Patients often know little about PHPs' and SHPs' responsibilities and duties in the care for patients with and after cancer. The 
Table 3 Factors affecting implementation of physical activity programmes among primary healthcare professionals

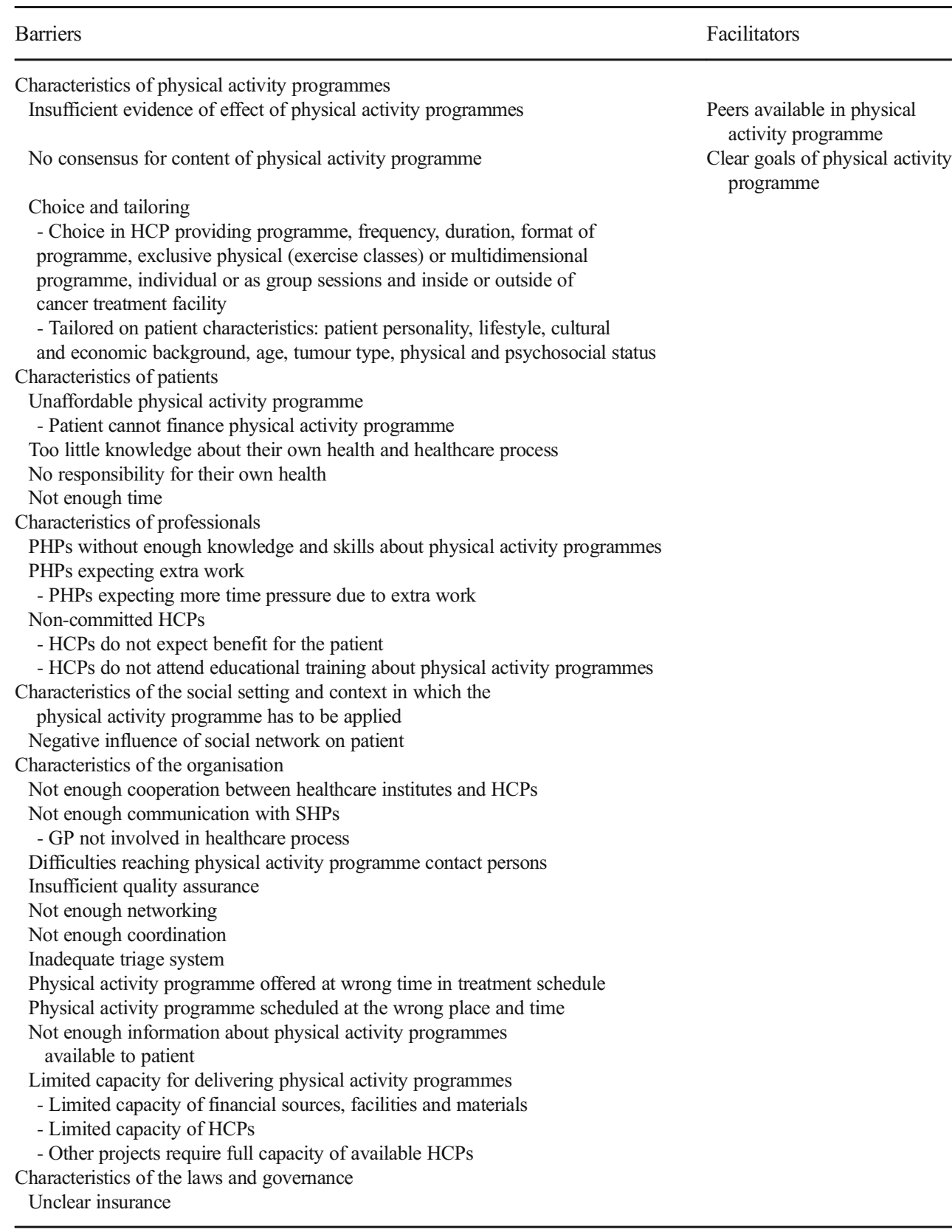

$H C P$ healthcare professional, $P H P$ primary healthcare professional, SHP secondary healthcare professional
PHPs and SHPs both believed that providing the right information for patients can increase their knowledge. However, some disagreed and said that not all patients were capable of understanding their own health and healthcare process. The PHPs were concerned that patients did not have enough time to participate in a physical activity programme during, but also after their cancer treatment. One quote regarding barriers in the domain of patients is:

"Uh, sometimes I do have the impression that it's difficult for patients to take responsibility. Some people have left it to others all their lives, as it were; others like medical people or us."

\section{Domain of HCPs}

Both the PHPs and the SHPs thought that GPs did not have enough knowledge and skills pertaining to the physical activity programmes to screen and successfully refer patients to physical activity programmes. They also felt that non-committed PHPs and SHPs hindered proper screening and referral. 
Table 4 Factors affecting the implementation of physical activity programmes among secondary healthcare professionals

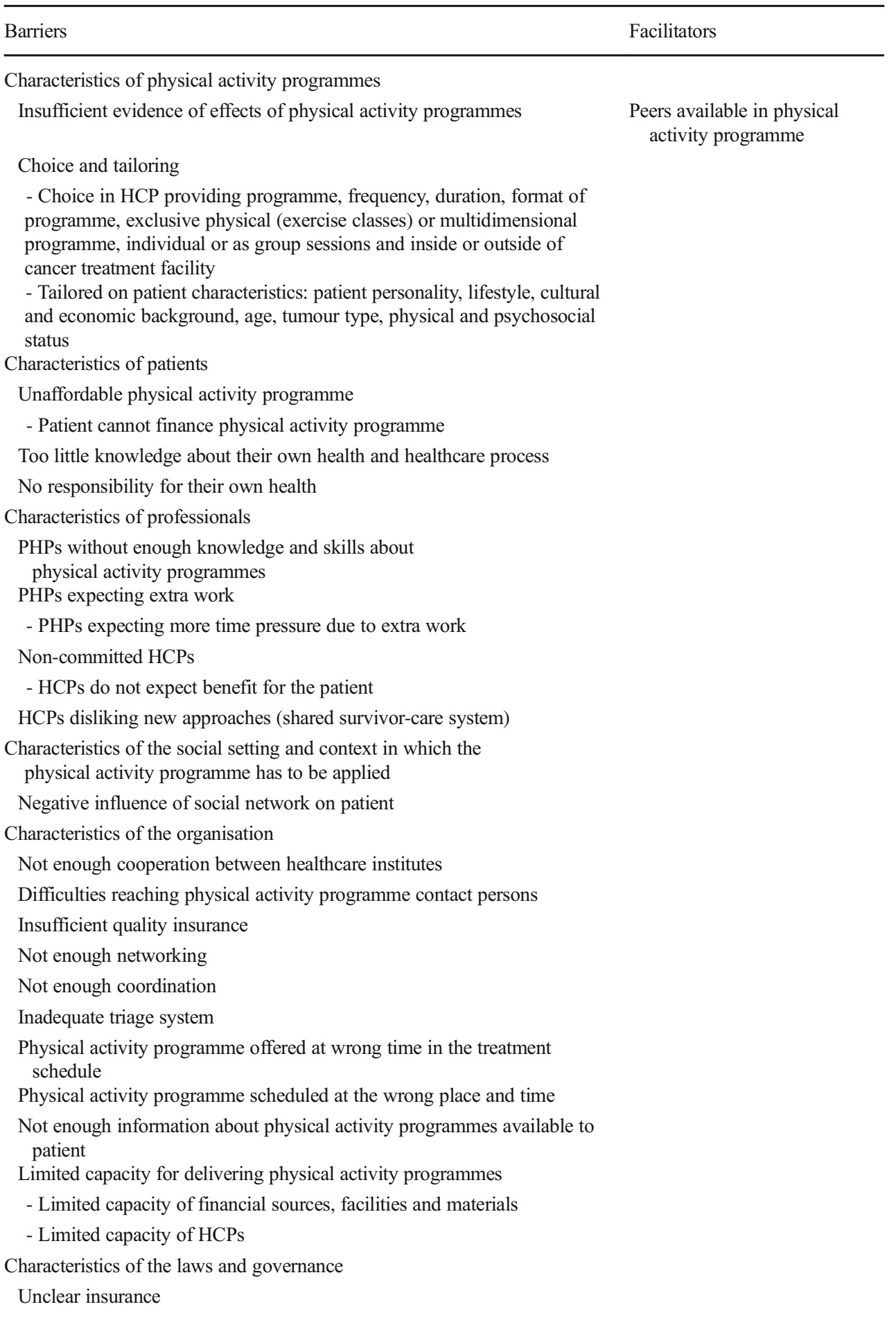

$H C P$ healthcare professional, $P H P$ primary healthcare professional, SHP secondary healthcare professional
GPs are mainly afraid of extra work if they take over the screening and referral for physical activity programmes in a shared-care model. The SHPs were concerned about PHPs and SHPs having a negative approach towards new thoughts, evidence of physical activity programmes, and a change of care model, such as the shift from the model of hospital care to a survivor shared-care model. The quote below illustrates the barriers in the domain of HCPs:

"What I sometimes also don't know is... when they ask, "OK, can I take up sports again? Can I start exercising?" Then I say, "Yes." "Yes, but the gynaecologist said I 
couldn't..." So, I really don't know your views of what patients can or cannot do."

\section{Domain of social setting}

In the social setting, both the PHPs and SHPs were concerned about the negative influence of the patient's social network. Peers, partners, family, friends, and neighbours do share their experiences and thoughts with patients, which does not always motivate the patients to join a physical activity programme.

Quotes illustrating this barrier in the social setting are:

"The best thing would be to get the social network of the patient involved in that. A partner with a negative attitude towards physical activity does not always motivate the patient to join"

\section{Domain of organisation}

Most of the PHPs' and SHPs' concerns were in the domain of organisation and were mainly about delivering the physical activity programmes in a shared-care model. We also found the biggest discrepancy between PHPs and SHPs in this domain.

The PHPs believed that the cooperation between PHPs and SHPs was not optimal. They explained that this was partly due to insufficient communication of SHPs towards PHPs. Especially the GPs felt that they were not involved, or involved too late, in the healthcare of their patients with cancer. Another challenge was contacting the SHPs and receiving the information about the patient's cancer history. Because there was no consensus about the roles in the survivor care, they could not fully cooperate in a shared-care model. Many PHPs were not sure whether the SHPs delivered proper survivor care, but they had no clear role for taking the responsibility to deliver it themselves.

When talking about cooperation and referral, many PHPs raised their concerns about inadequate networking with each other and with SHPs. They also had concerns about the quality assurance of the physical activity programmes. These circumstances made the GPs hesitate to cooperatively communicate and refer. Deliverers of physical activity programmes in primary care stated that the lack of a good network for GPs, SHPs, and each other impeded the referral of patients to them.

Remarkably, the SHPs only raised their concerns about inadequate cooperation and networks between healthcare institutes. They did not raise any concerns about poor cooperation or communication between themselves and the PHPs. Representative quotes that capture these barriers are:
"The boomerang effect! With the best of intentions, you refer a patient and then you get him back straight away... You can avoid that by having a case manager."

"Uh hmm. Yes I think that, especially in the multidisciplinary case, it is really important and that there should just be more reciprocal communication."

"That we know: in this discipline this is done, that discipline looks after that task, etc., that we tell each other what we are doing. So that the island feeling that we have now will disappear."

"If you don't continue the same policy, via the GP, then it could just be another wall for the patient."

\section{Domain of law and governance}

Most of the PHPs and SHPs recognised that it was unclear whether and what parts of the physical activity programmes were insured. There was too much variety of reimbursement, which made reimbursement unclear for both HCPs and patients. The HCPs could not fully inform the patients about the costs. They felt that this obscure reimbursement system eventually stopped patients from joining physical activity programmes. One quote illustrating the unclear insurancecoverage as a barrier is:

"The insurance is very important. Because the insurance does not cover a great many things. And it's really a horrible job for us to get everything all done."

\section{Discussion}

In this study with PHPs and SHPs involved in the screening, referral, and delivery of physical activity programmes in a shared-care model for survivors, we identified multiple barriers that hinder implementation. A physical activity programme that was not tailored to the patient impeded implementation, as did the inadequate knowledge and skills about physical activity programmes and the non-commitment of the HCPs. HCPs expressed their concerns about the negative influence of the patient's social network. Most barriers occurred in the domain of organisation. The HCPs were particularly concerned about the quality of collaboration and networks between hospitals. The insurance coverage was inadequate for physical activity programmes and information about what was covered was elusive. The PHPs raised concerns about lack of communication, 
unclear roles, and little collaboration with the SHPs, while, surprisingly, the SHPs did not raise such concerns.

An interesting finding was that all HCPs expressed their concerns about the negative influence of the patient's social network. More than $80 \%$ of cancer patients obtain treatment information and support from their social network [28, 29]. This network helps patients in understanding information, provides support and manages overall care that patients would otherwise not receive from their HCPs [28]. Most patients start and continue to do physical activities due to the emotional and practical support of their social network [30,31]. One should note that physical activity is still rarely a topic in daily clinical practice and patients may seek support from their social network. These findings may therefore be of importance and should lead to physical activity being included as a regular topic that needs attention in the regular care for cancer patients and survivors.

Surprisingly, we found that PHPs raised concerns about lack of communication, unclear roles, and scant collaboration with the SHPs, while the SHPs themselves did not raise such concerns. In other studies, lack of collaboration and miscommunication between PHPs and SHPs was also found, in both directions [32-36]. SHPs assigned this to the large number of PHPs, their varied level of commitment and knowledge, lack of time, and difficulties in contacting them [33]. PHPs thought this was due to lacking communication of patients' treatment information as well as SHPs who were not available for consultation when needed [34].

Concerns existed about the sustainability of the traditional model of delivering care to cancer survivors in secondary care. Sharing the delivery of this care with PHPs was seen as a solution. No differences were found in the quality of life or patient satisfaction [37], but survivors in the care of PHPs tend to receive more preventive care and appropriate care for co-morbidities. They have greater patient satisfaction than do survivors in the care of SHPs alone [38, 39]. There are also cost reductions due to fewer hospital appointments [40]. Nevertheless, most PHPs are less informed about the patients' cancer diagnoses and treatment history. They have had few experiences with cancer patients; they may be unaware of potential long-term complications of cancer and its treatment, and may be unprepared to handle them [41-43]. Our findings confirm that few PHPs and SHPs prefer a shared-care model for cancer survivors [17-21]. PHPs hesitate to take responsibility in this model because of their lack of experience with cancer patients and limited training in survivor care [18-21]. PHPs are also reluctant to accept such responsibilities because of the limited time they have to address cancer survivors' needs [19, 44]. From their perspective, SHPs are worried about the knowledge and skills of the PHPs for delivering proper screening, referral, and physical activity programmes [45]. The PHPs we interviewed explained that these concerns were enlarged by lack of communication, vague roles, poor networks, and little collaboration with the SHPs.

A shared-care model ensures that patients receive survivor care throughout treatment and along the continuum of cure and palliation. It puts PHPs and SHPs on the same team. Several studies report that team-based cancer care can improve patient outcomes and the quality of healthcare [46]. Some characteristics of a healthcare team that works well are: shared goals, clear roles, trust in each other, effective communication, leadership, and measurable processes and outcomes $[47,48]$. Our data and the literature show that these factors need improvement, especially the factors for clear roles, trust in each other, oneself, and effective communication.

Our data indicate the need of some on-going initiatives to facilitate implementation of physical activity programmes in a shared-care model. These initiatives include the use of survivor care plans, improving rehabilitation guidelines, improving networks, and the use of health information technology. During our interviews, the PHPs raised their concerns about lacking knowledge and little cooperation and communication with SHPs. Although little is yet known about the effects of survivor-care plans on patients outcomes, it is clear that such plans help PHPs provide survivor care with more confident $[19,21,22,49,50]$. They can also improve communication with SHPs, while providing PHPs with the necessary information.

Guidelines for rehabilitating patients with cancer are written quite generically. They do not give explicit recommendations or guidance about roles and responsibility. A guideline giving more specific guidance about what, when, which patient, which HCP, and why can guide both SHPs and PHPs to providing better care.

Health information technology can serve as a tool to facilitate efficiencies in shared-care. It can help to rapidly collect, share, and analyse data in an accessible, actionable, timely, customisable, and portable way between PHPs and SHPs [51]. Health information technology can help create networks for easy communication with qualified HCPs. It can help deliver easy access to patient records and allow HCPs to see each other's notes. Health information technology can also assist in clarifying roles by sending reminders to the right HCPs. It may help measure the quality of healthcare processes and outcomes. Several characteristics of health information technology can also help improve patient and caregiver engagement by providing patients' online access to their medical records, clinicians' notes, care plans, relevant clinical information about their health status, etc. [52]. Additionally, patients' self-reported health status, side effects of treatment, and sharing of other experiences as they occur [53] can help them become part of the shared-care team.

Implementing physical activity programmes in a sharedcare model requires changes at the policy level. Much 
literature focuses on the shortfall of SHPs in cancer care $[11,12]$. However, like the data in our study, other data show that PHPs do not have the capacity to manage the influx of cancer survivors who need physical activity programmes that would occur if the responsibility were transferred from a traditional SHP survivor-care model to a shared-care model $[45,54]$.

Other reasons for political changes are the insufficient insurance coverage, uncertainty and lack of information on the insurance coverage of physical activity programmes. Our current study suggests that insufficient and uncertain insurance coverage probably affects the implementation of physical activity programmes; this seems to be related as well to a lack of evidence regarding the most cost effective approaches. This requires better awareness, better evidence and advocacy of patients and professionals to better arrange reimbursement of physical activity programmes in cancer care. Providing survivors and their HCPs with clear information about insurance coverage and alternatives for the programmes with financial hurdles is an essential first step.

Our study has several strengths and limitations. The strength of qualitative methodology is that it can deliver a deeper understanding of the thought and experiences of individual HCPs [27, 55]. However, findings derived in a qualitative approach are harder to generalise to the broader population than findings derived in a quantitative approach.

We conducted 4 focus group interviews with 7, 7, 12 and 13 participants. Focus group interviews with more than 10 participants are difficult to control and they limit each person's opportunity to share insights and observations. In addition, group dynamics change when participants want to, but aren't able to describe their experiences. However group sizes can have as many as $12-15$ participants when there is a good moderator. We used an experienced moderator and experienced no problems concerning control and opportunities to share insights.

Our exploratory and qualitative approach to the focus group interviews of SHPs has the disadvantage of identifying the barriers and facilitators of the entire group of SHPs. This makes it hard to distinguish which differences exist in the views of the various professionals throughout the hospital (e.g. surgeons, radiotherapists, medical oncologists, gynaecologists, urologists, rehabilitation physicians, sportsmedicine physicians, physiotherapists, physician assistants, nurses and psychologists). Explorative studies performed among the different professionals separately would be a way of showing the contrast of barriers and facilitators between these different disciplines.

The HCPs in our study represented a diversity of hospitals in different regions in the Netherlands and may not necessarily reflect the situation of cancer survivor care in other countries. The incentive to start physical activity programmes might be different in other countries with different healthcare systems and often even more limited reimbursement policies. Although more research is needed to assess the nature of barriers and facilitators of physical activity programme implementation in other countries, our personal impression is that the findings may well be transferred to other countries.

Although the results of this study seem partly confirmatory, we think it adds relevant information, especially in view of the lagging implementation rates of physical activity programmes and scarce material on approaches to implement these programmes [56-59]. We are in need of more detailed and personalised suggestions for improvement. Results of a qualitative study that gives insight into potential barriers and facilitators [60] to tailor implementation strategies can thus be very helpful.

\section{Conclusion}

Most barriers to implementing physical activity programmes in a shared-care model for cancer survivors are in the domain of organisation: the collaboration, communication, networks and clear roles between PHPs and SHPs are currently inadequate. Survivor care plans, improved rehabilitation guidelines, smoothly functioning networks and more use of health information technology would all facilitate implementation. The knowledge gathered in this study can be used to develop a successful strategy for implementing physical activity programmes and improve the quality of cancer care.

Authors' contributions CIJ conducted the individual and focus group interviews, qualitatively analysed the data, drafted the manuscript and participated in the design and coordination of the study.

$\mathrm{RH}$ assisted to conduct the focus group interviews, conceived the study, and participated in its design and coordination, and helped draft the manuscript.

WRG helped draft the manuscript.

WH conceived the study, and participated in its design and coordination, and helped draft the manuscript.

PO participated in the design and coordination of the study, and helped draft the manuscript.

All authors read and approved the final manuscript.

Funding The Dutch Cancer Society supported this work (grant no. NKI 2010-4854)

\section{Compliance with ethical standards}

Competing interests The authors declare that they have no competing interests.

Ethics approval and consent to participate Our study concerns the ACare 2 programme. The Committee on Research Involving Human Subjects, Arnhem-Nijmegen region of the Netherlands, assessed the 
study and concluded that it would be carried out in accordance with the applicable rules concerning the review of research ethics committees and informed consent [register number 2014/211].

Abbreviations HCP, Healthcare professional; PHP, Primary healthcare professional; SHP, Secondary healthcare professional

Open Access This article is distributed under the terms of the Creative Commons Attribution 4.0 International License (http:// creativecommons.org/licenses/by/4.0/), which permits unrestricted use, distribution, and reproduction in any medium, provided you give appropriate credit to the original author(s) and the source, provide a link to the Creative Commons license, and indicate if changes were made.

\section{References}

1. Lee IM, Shiroma EJ, Lobelo F, Puska P, Blair SN, Katzmarzyk PT (2012) Lancet Physical Activity Series Working G: Effect of physical inactivity on major non-communicable diseases worldwide: an analysis of burden of disease and life expectancy. Lancet 380(9838):219-229

2. Mishra SI, Scherer RW, Geigle PM, Berlanstein DR, Topaloglu O, Gotay CC, Snyder C (2012) Exercise interventions on healthrelated quality of life for cancer survivors. Cochrane Database Syst Rev 8:CD007566

3. Cramp F, Byron-Daniel J (2012) Exercise for the management of cancer-related fatigue in adults. Cochrane Database Syst Rev 11: CD006145

4. Markes M, Brockow T, Resch KL (2006) Exercise for women receiving adjuvant therapy for breast cancer. Cochrane Database Syst Rev 4:CD005001

5. van Waart H, Stuiver MM, van Harten WH, Geleijn E, Kieffer JM, Buffart LM, de Maaker-Berkhof M, Boven E, Schrama J, Geenen MM, Meerum Terwogt JM, van Bochove A, Lustig V, van den Heiligenberg S, Smorenburg CH, Hellendoorn-van Vreeswijk J, Sonke GS, Aaronson NK (2015) Effect of low-intensity physical activity and moderate- to high-intensity physical exercise during adjuvant chemotherapy on physical fitness, fatigue, and chemotherapy completion rates: results of the PACES randomized clinical trial. J Clin Oncol 33(17):1918-1927

6. Kampshoff CS, Chinapaw MJ, Brug J, Twisk JW, Schep G, Nijziel MR, van Mechelen W, Buffart LM (2015) Randomized controlled trial of the effects of high intensity and low-to-moderate intensity exercise on physical fitness and fatigue in cancer survivors: results of the Resistance and Endurance exercise After ChemoTherapy (REACT) study. BMC Med 13:275

7. Stevinson C, Fox KR (2006) Feasibility of an exercise rehabilitation programme for cancer patients. Eur J Cancer Care (Engl) 15(4): 386-396

8. Courneya KS, Mackey JR, Bell GJ, Jones LW, Field CJ, Fairey AS (2003) Randomized controlled trial of exercise training in postmenopausal breast cancer survivors: cardiopulmonary and quality of life outcomes. J Clin Oncol 21(9):1660-1668

9. Segal R, Evans W, Johnson D, Smith J, Colletta S, Gayton J, Woodard S, Wells G, Reid R (2001) Structured exercise improves physical functioning in women with stages I and II breast cancer: results of a randomized controlled trial. J Clin Oncol 19(3):657-665

10. Segal RJ, Reid RD, Courneya KS, Malone SC, Parliament MB, Scott CG, Venner PM, Quinney HA, Jones LW, D'Angelo ME, Wells GA (2003) Resistance exercise in men receiving androgen deprivation therapy for prostate cancer. J Clin Oncol 21(9):16531659
11. Mariotto AB, Yabroff KR, Shao Y, Feuer EJ, Brown ML (2011) Projections of the cost of cancer care in the United States: 20102020. J Natl Cancer Inst 103(2):117-128

12. Yabroff KR, Lund J, Kepka D, Mariotto A (2011) Economic burden of cancer in the United States: estimates, projections, and future research. Cancer Epidemiol Biomark Prev 20(10):2006-2014

13. McCabe MS, Bhatia S, Oeffinger KC, Reaman GH, Tyne C, Wollins DS, Hudson MM (2013) American Society of Clinical Oncology statement: achieving high-quality cancer survivorship care. J Clin Oncol 31(5):631-640

14. van den Berg JP, Velthuis MJ, Gijsen BC, Lindeman E, van der Pol MA, Hillen HF: [Guideline "Cancer rehabilitation"]. Ned Tijdschr Geneeskd 2011, 155(51):A4104

15. Simard J, Kamath S, Kircher S (2019) Survivorship guidance for patients with colorectal Cancer. Curr Treat Options in Oncol 20(5): 38

16. Raaijmakers LG, Hamers FJ, Martens MK, Bagchus C, de Vries NK, Kremers SP (2013) Perceived facilitators and barriers in diabetes care: a qualitative study among health care professionals in the Netherlands. BMC Fam Pract 14:114

17. Cheung WY, Aziz N, Noone AM, Rowland JH, Potosky AL, Ayanian JZ, Virgo KS, Ganz PA, Stefanek M, Earle CC (2013) Physician preferences and attitudes regarding different models of cancer survivorship care: a comparison of primary care providers and oncologists. J Cancer Surviv 7(3):343-354

18. Potosky AL, Han PK, Rowland J, Klabunde CN, Smith T, Aziz N, Earle C, Ayanian JZ, Ganz PA, Stefanek M (2011) Differences between primary care physicians' and oncologists' knowledge, attitudes and practices regarding the care of cancer survivors. J Gen Intern Med 26(12):1403-1410

19. Kantsiper M, McDonald EL, Geller G, Shockney L, Snyder C, Wolff AC (2009) Transitioning to breast cancer survivorship: perspectives of patients, cancer specialists, and primary care providers. J Gen Intern Med 24(Suppl 2):S459-S466

20. Virgo KS, Lerro CC, Klabunde CN, Earle C, Ganz PA (2013) Barriers to breast and colorectal cancer survivorship care: perceptions of primary care physicians and medical oncologists in the United States. J Clin Oncol 31(18):2322-2336

21. Klabunde CN, Han PK, Earle CC, Smith T, Ayanian JZ, Lee R, Ambs A, Rowland JH, Potosky AL (2013) Physician roles in the cancer-related follow-up care of cancer survivors. Fam Med 45(7): 463-474

22. Bober SL, Recklitis CJ, Campbell EG, Park ER, Kutner JS, Najita JS, Diller L (2009) Caring for cancer survivors: a survey of primary care physicians. Cancer 115(18 Suppl):4409-4418

23. Tong A, Sainsbury P, Craig J (2007) Consolidated criteria for reporting qualitative research (COREQ): a 32-item checklist for interviews and focus groups. Int J Qual Health Care 19(6):349-357

24. Maarse H, Jeurissen P, Ruwaard D (2016) Results of the marketoriented reform in the Netherlands: a review. Health Econ Policy Law 11(2):161-178

25. Grol R, Wensing M (2004) What drives change? Barriers to and incentives for achieving evidence-based practice. Med J Aust 180(6 Suppl):S57-S60

26. Flottorp SA, Oxman AD, Krause J, Musila NR, Wensing M, Godycki-Cwirko M, Baker R, Eccles MP (2013) A checklist for identifying determinants of practice: a systematic review and synthesis of frameworks and taxonomies of factors that prevent or enable improvements in healthcare professional practice. Implement Sci 8:35

27. Elo S, Kyngas H (2008) The qualitative content analysis process. J Adv Nurs 62(1):107-115

28. Sahay TB, Gray RE, Fitch M (2000) A qualitative study of patient perspectives on colorectal cancer. Cancer Pract 8(1):38-44

29. Arora NK, Finney Rutten LJ, Gustafson DH, Moser R, Hawkins RP (2007) Perceived helpfulness and impact of social support provided 
by family, friends, and health care providers to women newly diagnosed with breast cancer. Psychooncology 16(5):474-486

30. Adamsen L, Andersen C, Lillelund C, Bloomquist K, Moller T (2017) Rethinking exercise identity: a qualitative study of physically inactive cancer patients' transforming process while undergoing chemotherapy. BMJ Open 7(8):e016689

31. Husebo AM, Karlsen B, Allan H, Soreide JA, Bru E (2015) Factors perceived to influence exercise adherence in women with breast cancer participating in an exercise programme during adjuvant chemotherapy: a focus group study. J Clin Nurs 24(3-4):500-510

32. Lewis RA, Neal RD, Hendry M, France B, Williams NH, Russell D, Hughes DA, Russell I, Stuart NS, Weller D, Wilkinson C (2009) Patients' and healthcare professionals' views of cancer follow-up: systematic review. Br J Gen Pract 59(564):e248-e259

33. Wood ML, McWilliam CL (1996) Cancer in remission. Challenge in collaboration for family physicians and oncologists. Can Fam Physician 42:899-904 907-810

34. Anvik T, Holtedahl KA, Mikalsen H (2006) "When patients have cancer, they stop seeing me"-the role of the general practitioner in early follow-up of patients with cancer-a qualitative study. BMC Fam Pract 7:19

35. Johansson B, Berglund G, Hoffman K, Glimelius B, Sjoden PO (2000) The role of the general practitioner in cancer care and the effect of an extended information routine. Scand J Prim Health Care 18(3):143-148

36. Jiwa M, Thompson J, Coleman R, Reed M (2006) Breast cancer follow-up: could primary care be the right venue? Curr Med Res Opin 22(4):625-630

37. Wattchow DA, Weller DP, Esterman A, Pilotto LS, McGorm K, Hammett Z, Platell C, Silagy C (2006) General practice vs surgical-based follow-up for patients with colon cancer: randomised controlled trial. Br J Cancer 94(8):1116-1121

38. Snyder CF, Earle CC, Herbert RJ, Neville BA, Blackford AL, Frick KD (2008) Preventive care for colorectal cancer survivors: a 5-year longitudinal study. J Clin Oncol 26(7):1073-1079

39. Jacobs LA, Palmer SC, Schwartz LA, DeMichele A, Mao JJ, Carver J, Gracia C, Hill-Kayser CE, Metz JM, Hampshire MK, Vachani C, Pucci D, Meadows AT (2009) Adult cancer survivorship: evolution, research, and planning care. CA Cancer J Clin 59(6):391-410

40. Smith SM, Allwright S, O'Dowd T (2008) Does sharing care across the primary-specialty interface improve outcomes in chronic disease? A systematic review. Am J Manag Care 14(4):213-224

41. Nekhlyudov L (2009) "doc, should I see you or my oncologist?": a primary care perspective on opportunities and challenges in providing comprehensive care for cancer survivors. J Clin Oncol 27(15): 2424-2426

42. Nekhlyudov L, Aziz NM, Lerro C, Virgo KS (2013) Oncologists' and primary care physicians' awareness of late and long-term effects of chemotherapy: implications for care of the growing population of survivors. J Oncol Pract

43. Dulko D, Pace CM, Dittus KL, Sprague BL, Pollack LA, Hawkins NA, Geller BM (2013) Barriers and facilitators to implementing cancer survivorship care plans. Oncol Nurs Forum 40(6):575-580

44. Hewitt ME, Bamundo A, Day R, Harvey C (2007) Perspectives on post-treatment cancer care: qualitative research with survivors, nurses, and physicians. J Clin Oncol 25(16):2270-2273
45. Neuman HB, Jacobs EA, Steffens NM, Jacobson N, Tevaarwerk A, Wilke LG, Tucholka J, Greenberg CC (2016) Oncologists' perceived barriers to an expanded role for primary care in breast cancer survivorship care. Cancer medicine 5(9):2198-2204

46. Boult C, Green AF, Boult LB, Pacala JT, Snyder C, Leff B (2009) Successful models of comprehensive care for older adults with chronic conditions: evidence for the Institute of Medicine's "retooling for an aging America" report. J Am Geriatr Soc 57(12): 2328-2337

47. Wynia MK, Von Kohorn I, Mitchell PH (2012) Challenges at the intersection of team-based and patient-centered health care: insights from an IOM working group. JAMA 308(13):1327-1328

48. Babiker A, El Husseini M, Al Nemri A, Al Frayh A, Al Juryyan N, Faki MO, Assiri A, Al Saadi M, Shaikh F, Al Zamil F (2014) Health care professional development: working as a team to improve patient care. Sudan J Paediatr 14(2):9-16

49. Dawes AJ, Hemmelgarn M, Nguyen DK, Sacks GD, Clayton SM, Cope JR, Ganz PA, Maggard-Gibbons M (2015) Are primary care providers prepared to care for survivors of breast cancer in the safety net? Cancer 121(8):1249-1256

50. Del Giudice ME, Grunfeld E, Harvey BJ, Piliotis E, Verma S (2009) Primary care physicians' views of routine follow-up care of cancer survivors. J Clin Oncol 27(20):3338-3345

51. Cipriano PF, Bowles K, Dailey M, Dykes P, Lamb G, Naylor M (2013) The importance of health information technology in care coordination and transitional care. Nurs Outlook 61(6):475-489

52. Walker J, Leveille SG, Ngo L, Vodicka E, Darer JD, Dhanireddy S, Elmore JG, Feldman HJ, Lichtenfeld MJ, Oster N, Ralston JD, Ross SE, Delbanco T (2011) Inviting patients to read their doctors' notes: patients and doctors look ahead: patient and physician surveys. Ann Intern Med 155(12):811-819

53. Cheng C, Stokes TH, Wang MD (2011) caREMOTE: the design of a cancer reporting and monitoring telemedicine system for domestic care. Conf Proc IEEE Eng Med Biol Soc 2011:3168-3171

54. Petterson SM, Liaw WR, Phillips RL Jr, Rabin DL, Meyers DS, Bazemore AW (2012) Projecting US primary care physician workforce needs: 2010-2025. Ann Fam Med 10(6):503-509

55. Hsieh HF, Shannon SE (2005) Three approaches to qualitative content analysis. Qual Health Res 15(9):1277-1288

56. Segal R, Evans W, Johnson D, Smith J, Colletta SP, Corsini L, Reid R (1999) Oncology Rehabilitation Program at the Ottawa Regional Cancer Centre: program description. CMAJ 161(3):282-285

57. Demark-Wahnefried W (2007) Print-to-practice: designing tailored print materials to improve cancer survivors' dietary and exercise practices in the FRESH START trial. Nutr Today 42(3):131-138

58. Grabois M (2001) Integrating cancer rehabilitation into medical care at a cancer hospital. Cancer 92(4 Suppl):1055-1057

59. Schmidt KD (2001) Cancer rehabilitation services in a tertiary care center. Cancer 92(4 Suppl):1053-1054

60. IJsbrandy C, Hermens RPMG, Boerboom LWM, Gerritsen WR, van Harten WH, Ottevanger PB (2019) Implementing physical activity programs for patients with cancer in current practice: patients' experienced barriers and facilitators. J Cancer Surviv

Publisher's note Springer Nature remains neutral with regard to jurisdictional claims in published maps and institutional affiliations. 


\section{Affiliations}

\section{Charlotte IJsbrandy ${ }^{1,2,3}$ - Wim H. van Harten ${ }^{4,5}$ • Winald R. Gerritsen ${ }^{2} \cdot$ Rosella P.M.G. Hermens $^{1}$ •}

\section{Petronella B. Ottevanger ${ }^{2}$}

1 Radboud Institute for Health Science (RIHS), Scientific Institute for Quality of Healthcare (IQ healthcare), Radboud University Medical Center Nijmegen, PO Box 9101, 6500 HB Nijmegen, The Netherlands

2 Radboud Institute for Health Science (RIHS), Department of Medical Oncology, Radboud University Medical Center Nijmegen, PO Box 9101, 6500 HB Nijmegen, The Netherlands

3 Radboud Institute for Health Science (RIHS), Department of Radiation Oncology, Radboud University Medical Center Nijmegen, PO Box 9101, 6500 HB Nijmegen, The Netherlands
4 Netherlands Cancer Institute, Division of Psychosocial Research and Epidemiology, Plesmanlaan 121, 1066

CX Amsterdam, The Netherlands

5 Department of Health Technology and Services Research, University of Twente, MB-HTSR, PO Box 217, 7500

AE Enschede, The Netherlands 